INTESTINE INFLAMMATION

\title{
Proinflammatory cytokines increase glial fibrillary acidic protein expression in enteric glia
}

\author{
G B T von Boyen, M Steinkamp, M Reinshagen, K-H Schäfer, G Adler, J Kirsch
}

Gut 2004;53:222-228. doi: 10.1136/gut.2003.012625

See end of article for authors' affiliations

.....................

Correspondence to: Professor J Kirsch, Department of Anatomy and Cellular

Neurobiology, University of Ulm, Albert-EinsteinAllee 11, $89069 \mathrm{Ulm}$, Germany; joachim. kirsch@medizin.uni-ulm.de

Accepted for publication 2 September 2003
Background: Enteric glia protect the integrity of the gut, as loss of enteric glial fibrillary acidic protein (GFAP) positive (+) glia leads to a haemorrhagic jejunoileitis. Crohn's disease (CD) and necrotising enterocolitis (NEC) show pathological changes in enteric glia. Therefore, factors controlling GFAP+ enteric glia are of great interest. The aim of the present study was to characterise enteric glia and determine the effect of interleukin $1 \beta$ (IL-1 $\beta)$, interleukin 4 (IL-4), tumour necrosis factor $\alpha$ (TNF- $\alpha)$, and lipopolysaccharides (LPS) on cultured enteric glia.

Methods: Dissected rat colon and cultured enteric glia cells were double labelled with anti-GFAP and antiS-100 antibodies. For regulatory studies, enteric glia cells were treated with cytokines and LPS. Proliferation was assayed using bromodeoxyuridine (BrdU) and mitosis of enteric glia was blocked by demecolcine.

Results: We were able to distinguish GFAP negative (-) from GFAP+ glia subtypes in situ and in primary cultures. Incubation of cells with IL-1 $\beta$, TNF- $\alpha$, and LPS led to a significant increase in GFAP+ enteric glia while IL- 4 had no effect on GFAP expression. After incubation with IL-1 $\beta$, total intracellular GFAP of enteric glia cells was increased. Upregulation of GFAP+ enteric glia could also be observed after stimulation with IL-1 $\beta$ on blocking mitosis. BrdU uptake in stimulated enteric glia showed no increased proliferation rate. Conclusions: Two different types of enteric glia based on GFAP expression exist in the gut. Proinflammatory cytokines and LPS cause a dramatic increase in GFAP+ enteric glia. This suggests that cytokines play an important role in controlling GFAP+ enteric glia which might in turn be involved in modulating the integrity of the bowel during inflammation. l: ncreased GFAP expression has been observed in inflammation $^{12}$ or inflammatory diseases of the gut, such as ulcerative colitis. ${ }^{3}$ This increase is also evident but much less pronounced in inflamed tissues of patients with Crohn's disease $(C D) .^{3} \mathrm{CD}$ is a chronic spontaneously relapsing disorder of unknown origin. The characteristics of CD include a Thl response and transmural inflammation affecting all layers of the bowel wall, including the enteric nervous system (ENS). ${ }^{45}$ Although there are controversial data on the number of ENS cells in intestinal inflammation or CD, recent work shows that ENS damage in uninflamed tissues of patients with CD is characterised by severe disruption of enteric glia cell networks, which seem to respond poorly to inflammatory signals. ${ }^{36}$ A significant reduction in glial cells of the myenteric and submucosal plexus ${ }^{7}$ is also one of the histopathological features of necrotising enterocolitis (NEC). This ischaemic and necrotic inflammation of the gut, most commonly involving the terminal ileum and proximal colon, is a major cause of paediatric morbidity and mortality within neonatal intensive care. ${ }^{8}$ The pathogenesis of both diseases (CD and NEC) is still unknown.

The crucial role of enteric glia in gut homeostasis was convincingly demonstrated by induction of a fatal haemorrhagic jejunoileitis in a transgenic mouse model lacking enteric glial fibrillary acidic protein (GFAP) positive $(+)$ glia. ${ }^{9}$ The intestinal histopathology showed similarities to those described in CD and NEC. ${ }^{69}$ The mechanisms underlying the role of enteric glia for homeostasis of the gut remain unclear, as little is known about enteric glia cells and their role during inflammation. ${ }^{10}{ }^{11}$ However, one could speculate that failure of enteric glia to respond adequately to noxious stimuli could participate in the pathological changes of CD and NEC.

The ENS and the enteric glia are part of the peripheral nervous system. Nevertheless, enteric glia differ markedly from other glia cells in the peripheral nervous system and resemble central nervous system (CNS) astrocytes with respect to S-100 protein and GFAP expression. ${ }^{12-16}$ Two classes of astrocytes can be distinguished in the CNS, which may have corresponding subtypes in the ENS, namely the GFAP+ group expressing high levels of GFAP and a GFAP negative (-) group. ${ }^{15}{ }^{16}$ As the number of these GFAP+ cells is upregulated in almost all types of CNS injury, a condition known as astrogliosis, GFAP+ astrocytes seem to be the major astrocytic form. ${ }^{17} 18$

Although it is well established that astrogliosis and failure of astrocytic glia function appear to play an important role in the pathogenesis of many disorders of the CNS, ${ }^{19}{ }^{20}$ it is not known whether similar mechanisms mediated by enteric glia exist in the gut. Astrogliosis can be induced by cytokines and lipopolysaccharides (LPS). ${ }^{21-23}$ The latter also trigger the immune responses in the gut and lead to the release of interleukin $1 \beta$ (IL- $1 \beta$ ) and tumour necrosis factor $\alpha$ (TNF- $\alpha$ ). These proinflammatory cytokines are also known to be highly upregulated in CD and NEC and seem to be important mediators of the inflammatory response in the gut. ${ }^{62425}$ The effect of proinflammatory cytokines in situ may be modulated by cytokines with anti-inflammatory potency-for example, interleukin 4 (IL-4), which is decreased in CD. ${ }^{26}$

Here we show that, similar to the situation in the CNS, different glia forms exist in the gut and proinflammatory

Abbreviations: $C D$, Crohn's disease; ENS, enteric nervous system; NEC, necrotising enterocolitis; GFAP, glial fibrillary acidic protein; CNS, central nervous system; IL, interleukin; LPS, lipopolysaccharides; TNF, tumour necrosis factor; MEM, minimal essential medium; PBS, phosphate buffered saline; BrdU, bromodeoxyuridine 
cytokines and LPS can control the number of GFAP+ enteric glia, which may be essential for the integrity of the bowel.

\section{MATERIAL AND METHODS \\ Tissue preparation of rat colon}

Eight Wistar rats were killed by $\mathrm{CO}_{2}$ asphyxiation. The distal colon was dissected and fixed in 4\% PFA, paraffin embedded, and processed for immunohistochemical analysis, as described below. Twelve independent sections per animal were analysed. As the epithelial crypts were weakly labelled by the immunofluorescence method employed in our study, there was full visual control over the orientation of the section and GFAP+ and S100+ cells underneath the epithelium were identified as enteric glia of the "plexus mucosus".

\section{Dissociated myenteric plexus cultures}

Newborn rats (Wistar strain) were deeply anaesthetised by ether and decapitated. The intestines were removed and the myenteric plexus was isolated using the method of Schafer and colleagues. ${ }^{27}$ In brief, small intestines were rinsed in sterile minimal essential medium (MEM) with $25 \mathrm{mM}$ HEPES buffer (Gibco Life Technologies). The muscle layer containing the myenteric plexus was stripped from the mucosa. The tissue was incubated in a collagenase solution (CL type II $1 \mathrm{mg} / \mathrm{ml}$; Gibco Life Technologies) in Hanks balanced salt solution (Gibco Life Technologies) for 1.5 hours at $37^{\circ} \mathrm{C}$. The disintegrated tissue was vortexed and the isolated parts of the myenteric plexus were stored in MEMHEPES on ice. The collected pieces were incubated in trypsin $\left(0.1 \mathrm{mg} / \mathrm{ml}\right.$; Gibco Life Technologies) for 15 minutes at $37^{\circ} \mathrm{C}$ and then centrifuged at $750 \mathrm{rpm}$. The trypsin reaction was stopped by adding fetal calf serum (Gibco Life Technologies). Cells were then plated on polyornithine coated $(0.5 \mathrm{mg} / \mathrm{ml}$; Sigma Chemical Co., St Louis, Missouri, USA) coverslips and were topped with $450 \mu \mathrm{l}$ DMEM-F-12 (Gibco Life Technologies). The cultures were kept in a humidified atmosphere of $95 \%$ air $/ 5 \% \mathrm{CO}_{2}$ at $37^{\circ} \mathrm{C}$, incubated with $10 \%$ fetal calf serum. At day 3, the culture consisted of approximately $98 \%$ of enteric glia, as judged by immunolabelling with mouse antibody specific for GFAP and rabbit antibody for S-100 protein. In addition, few fibroblasts and neurones were present in our cultures.

In vitro experiments using IL- $1 \beta$, anti-IL- $1 \beta$, IL- 1 receptor antagonist, TNF- $\alpha$, LPS, and IL-4

To study the effects of cytokines and LPS on GFAP in enteric glia, cell cultures were incubated with IL-1 $\beta$ ( $1-150 \mathrm{ng} / \mathrm{ml})$, TNF- $\alpha(60 \mathrm{pg} / \mathrm{ml})$ (R\&D Systems), LPS (10 $\mu \mathrm{g} / \mathrm{ml})$ (Sigma), or IL-4 $(10 \mathrm{ng} / \mathrm{ml})$ (R\&D Systems) in culture medium for 32 hours at $37^{\circ} \mathrm{C}$. Control cells were incubated with medium only. After 1, 8, 16, 24, and 32 hours, cell cultures were fixed. To study the specific effect of IL-1 $\beta$, cell cultures were preincubated with $20 \mu \mathrm{g} / \mathrm{ml}$ anti-IL- $1 \beta$ or with $1 \mu \mathrm{g} / \mathrm{ml}$ IL- 1 receptor antagonist (R\&D Systems) for two hours. Cultures were stimulated for 32 hours with IL-1 $\beta$ and cells were fixed. In other experiments cells were stimulated for 32 hours with IL- $1 \beta$, then the medium was removed and replaced by medium containing $1 \mu \mathrm{g} / \mathrm{ml}$ IL- 1 receptor antagonist (R\&D Systems) for 24 hours. Control cultures received the same volume of drug solvent only. Cell cultures were investigated by indirect immunofluorescence and western blotting. In each experiment, measurements were performed in duplicate. Identical experiments were repeated six times.

\section{In vitro experiments using demecolcine}

Glia cell cultures were incubated with demecolcine (SigmaAldrich) to stop mitosis by using a final concentration of $5 \mu \mathrm{g} / \mathrm{ml}$. Then, cell cultures were incubated with 10, 20, 50, and $80 \mathrm{ng} / \mathrm{ml}$ IL- $1 \beta$ (R\&D Systems). Control cells were incubated with DMEM-F-12 or demecolcine only. After 24 hours, cells were fixed or were used for western blotting.

\section{Indirect immunofluorescence of dissected rat colon}

Tissue sections were deparaffinised and permeabilised with phosphate buffered saline (PBS) $/ 0.3 \%$ Triton $\times 100$. Slides were blocked with $1 \%$ bovine serum (Sigma) in PBS. Antibodies against GFAP (Pharmingen; mouse, diluted 1:200) and S-100 protein (Dako; rabbit, diluted 1:100) were incubated overnight at $4^{\circ} \mathrm{C}$. After washing in PBS/0.1\% Tween 20, slides were incubated with the appropriate secondary antibodies: Alexa 488 coupled goat antimouse IgG (Sigma; diluted 1:600) and cy3 coupled goat antirabbit IgG (Sigma; diluted 1:600) After washing in PBS, slides were embedded in glycerol gelatin. Control labelling was performed with omission of the first antibodies to ensure that there was no unspecific labelling of cells.

\section{Indirect immunofluorescence of enteric glia cell cultures}

Enteric glia cells of each animal were pooled and cultured on 20 different coverslips. Cell cultures were fixed and permeabilised with $90 \%$ methanol, $10 \%$ acetic acid cooled to $-40{ }^{\circ} \mathrm{C}$. After washing in PBS, cells were blocked with $1 \%$ bovine serum ( Sigma) over 40 minutes. GFAP (Pharmingen; diluted 1:200) and S-100 protein (Dako; diluted 1:100) antibodies were incubated for one hour at room temperature. Double immunofluorescence staining was done by combining rabbit (S-100) and mouse (GFAP) primary antibodies and then combining the secondary antibodies goat antimouse IgG (Sigma; cy3, diluted 1:600) for GFAP and goat antirabbit IgG (Sigma; Alexa 488, diluted 1:600) for S-100. After immunostaining, coverslips were mounted cell side down on microscope slides using moviol. S-100 and GFAP labelling of astrocytic cultures served as positive controls (data not shown).

Tissue sections and cell cultures were analysed using a Leica confocal laser scanning microscope. For determining the population of GFAP enteric glia, 10 visual fields were randomly selected for each coverslip or slide. In each field the numbers of S-100+ cells and GFAP+ cells were counted; their difference showed the GFAP- enteric glia portion. Similarly, the contingent of GFAP+ enteric glia was counted after stimulation with IL- $1 \beta$, TNF- $\alpha$, LPS, and IL-4.

\section{BrdU incorporation}

To assess enteric glia proliferation, a double immunofluorescence GFAP/bromodeoxyuridine (BrdU; Sigma) technique was used. ${ }^{28}$ Cultures were incubated with IL-1 $\beta(5,10,20,50$, 80 , and $100 \mathrm{ng} / \mathrm{ml}$ ) for 32 hours, with $10 \mu \mathrm{M}$ BrdU added, so that proliferating cells may incorporate this label. Cultures were then immunolabelled (anti-BrdU (Becton-Dickinson), l:400 anti-GFAP (Pharmingen)), coded, and analysed using a Leica confocal laser scanning microscope. Negative controls for staining included omission of both primary antibodies and cultures without addition of BrdU. To quantify proliferation, the percentage of GFAP+ enteric glia that had BrdU labelling in their nuclei was determined. Incorporation of BrdU was determined as $100 \%$ in controls.

\section{Data analysis}

Evaluation of the ratio of GFAP+ /GFAP - enteric glia and of BrdU incorporation was performed in a blinded fashion by two raters. For all measurements, inter-rater reliability ranged from 0.87 to $0.98(\mathrm{p}<0.0001)$. All data are expressed as mean (SEM) values. Statistical comparison between GFAP+ and GFAP - enteric glia and between GFAP+ /BrdU positive cells was carried out by a non-parametric two tailed 
Mann-Whitney $U$ test, with $\mathrm{p} \leqslant 0.05$ considered as an indicator of significance.

\section{Western blot analysis}

Enteric glia cells were harvested and washed twice with ice cold PBS. Cells were incubated in a lysis buffer on ice for 30 minutes and then sonicated. Western blotting was performed as described previously. ${ }^{29}$ The results of three independent experiments are shown.

Western blots were analysed by scanning densitometry. Multiple exposures of each blot were used to obtain grey scale images and the GFAP (Pharmingen) immunoreactive bands were quantified with the Quantity One Analysis program from Bio-Rad.

\section{RESULTS}

\section{Double immunolabelling with S-100 and GFAP in vivo} and in vitro

Enteric glia cells were identified immunocytochemically by expression of the glial cell specific marker protein S-100 (fig 1A, C). Enteric glia cell S-100 labelling was observed in the cytoplasm and nucleus (13; fig 1B, C) whereas GFAP labelling showed typical intermediate filament networks (fig 1C, D). Cultured immunopositive cells were usually bior tripolar, with long thin processes connecting each other, or alternatively, flattened with extended cytoplasm (fig ID, E). Multipolar shaped cells, but not flattened cells, were easily distinguished from unstained fibroblasts (fig $1 F$ ). In tissue sections, only $54(10) \%$ of all S-100 positive enteric glia simultaneously expressed GFAP (fig 1A, B, fig 3A). Similar results $(61(4) \%)$ were found for GFAP+ enteric glia in cell cultures (see fig 3A). Cultured GFAP+ and GFAP - enteric glia could not be distinguished by morphology. Both cell types showed multipolar and flattened cell forms. GFAPcells were frequently seen in the periphery of pseudo ganglia formed in culture whereas GFAP+ cells were found next to neurones in the centre of pseudoganglia (data not shown).

\section{Effect of IL-1 $\beta$, TNF- $\alpha$, LPS, and IL-4 on regulation of GFAP+ enteric glia}

Addition of IL- $1 \beta$ to the culture medium significantly increased the ratio of GFAP+ glia cells $(p<0.01$ ) (figs 2, $3 \mathrm{~A})$. Whereas in untreated controls $61(4) \%$ of enteric glia were GFAP+ and 39 (5)\% GFAP- , addition of $80 \mathrm{ng} / \mathrm{ml}$ IL- $1 \beta$ shifted the ratio of GFAP+ enteric glia to $88(7) \%$ and reduced the GFAP - glia pool to 12 (3)\% (fig 3A). To examine whether this effect was specific for IL- $1 \beta$, a neutralising antibody $(20 \mu \mathrm{g} / \mathrm{ml}$ anti-IL- $1 \beta)$ to IL- $1 \beta$ or the IL- 1 receptor antagonist $(1 \mu \mathrm{g} / \mathrm{ml})$ was preincubated for 30 minutes at $37^{\circ} \mathrm{C}$ before addition of $80 \mathrm{ng} / \mathrm{ml}$ IL- $1 \beta$ to enteric glia cultures. After treatment with anti-IL-1 $\beta$ or IL-1 receptor antagonist, the stimulating effect of IL- $1 \beta$ was completely abolished with similar numbers of GFAP+ enteric glia cells. Furthermore, anti-IL-1 $\beta$ had no effect on the GFAP+ enteric glia subpopulation compared with controls (fig 3A). In order to corroborate our finding, we tested whether a similar effect could be seen after stimulation with another proinflammatory cytokine TNF- $\alpha$, or LPS or IL- 4 . TNF- $\alpha$ caused greater upregulation of GFAP+ enteric glia (84 (8)\%; p <0.01), which was also found after incubation with LPS (94 (5)\%; p<0.01) (fig 3A). Exposure to IL-4 had no increasing effect on GFAP+ enteric glia while a slight decrease in GFAP+ cells was found but this was not statistically significant (56 (3)\%) (fig 3A).

Dose dependence of GFAP+ enteric glia due to IL-1 $1 \beta$ Increasing concentrations of $\mathrm{IL}-1 \beta(1,5,10,20,50$, and $80 \mathrm{ng} / \mathrm{ml}$ ) enhanced the GFAP+ enteric glia pool, plateauing at an IL- $1 \beta$ concentration of $80 \mathrm{ng} / \mathrm{ml}$. Doses of 100 or
$150 \mathrm{ng} / \mathrm{ml}$ had no additional effect on GFAP+ enteric glia (fig 3B).

\section{Time course of increased GFAP+ enteric glia after incubation with IL-1 $\beta$}

Figure 3C show the time course of increased GFAP+ enteric glia after incubation with IL-1 $\beta(80 \mathrm{ng} / \mathrm{ml})$. The number of GFAP+ enteric glia increased continuously for 24 hours, reaching a plateau, which could indicate that protein synthesis is required for GFAP upregulation. Withdrawal of IL- $1 \beta$ after 32 hours caused significant downregulation of GFAP+ enteric glia cell numbers (68 (4)\%) 24 hours later. These data show that upregulation of GFAP+ enteric glia by IL- $1 \beta$ is reversible.

\section{Amount of GFAP expression in enteric glia}

Western blot analysis of extracts from untreated primary enteric glia cell cultures revealed a weak basal expression of GFAP. After incubation with 10 and $20 \mathrm{ng} / \mathrm{ml}$ IL- $1 \beta$, GFAP expression was significantly upregulated by a factor of 2 and 4 , as revealed by densitometry. Treatment with 80 or $100 \mathrm{ng} / \mathrm{ml}$ IL- $1 \beta$ induced an additional increase in GFAP content in enteric glia cultures (by a factor of 6). Again, blocking IL$1 \beta$ by a specific antibody abolished GFAP upregulation in cultures (fig 4A).

\section{GFAP upregulation by GFAP expression in GFAP - enteric glia}

At a dose of $5 \mu \mathrm{g} / \mathrm{ml}$, demecolcine blocked mitosis of glia cells in metaphase. Treatment with $5 \mu \mathrm{g} / \mathrm{ml}$ demecolcine for 12 hours did not alter basal GFAP expression levels, as determined by semiquantitative western blotting. Likewise, GFAP expression was increased to comparable levels by IL-1 $\beta$ stimulation, also in the presence of demecolcine (fig 4B). Similar data were found when immunolabelling was used for quantification of GFAP expression: control+demecolcine 61 (4)\%; IL-1 $\beta+$ demecolcine 87 (6)\% (fig 3A).

\section{Proliferation of GFAP+ enteric glia}

Addition of IL-1 $\beta$ to the culture medium in different concentrations $(5,20,50,80,100$, and $150 \mathrm{ng} / \mathrm{ml})$ showed no significant difference in BrdU uptake compared with controls. However, high doses of IL-1 $\beta \quad(50,80,100$, and $150 \mathrm{ng} / \mathrm{ml}$ ) did not increase the proliferation rate of primary enteric glia but decreased BrdU uptake slightly (fig 5).

\section{DISCUSSION}

In the present study, we showed that both GFAP+ and GFAP - types of enteric glia are present in the normal rodent gut. Proinflammatory cytokines and LPS strongly upregulated the number of GFAP+ glia cells by increasing GFAP expression in GFAP- enteric glia cells. The cytokine IL-4 had no effect on GFAP expression. These regulatory processes may play a role in protecting the gut from inflammation, intraluminal haemorrhage, and degeneration of enteric neurones.

The enteric glia strongly resemble astrocytic glia in the CNS, which can be divided into two forms, depending on GFAP expression. GFAP - astrocytes represent 30-50\% of CNS glia. ${ }^{15}{ }^{16}$ Here we identified a GFAP - subpopulation of enteric glia in the ENS. As revealed by immunohistochemistry, the ratio of GFAP - and GFAP+ enteric glia in vivo was similar to that in our cultures, indicating that the relative numbers of the respective glia subpopulations were not significantly altered under our culture conditions. In the ENS, approximately $40-50 \%$ of enteric glia cells are GFAP- , which is similar to that reported for astrocytes in the CNS, 15 í whereas in both the CNS and ENS GFAP+ astrocytes represent the major glia form (approximately 50-60\%). One 

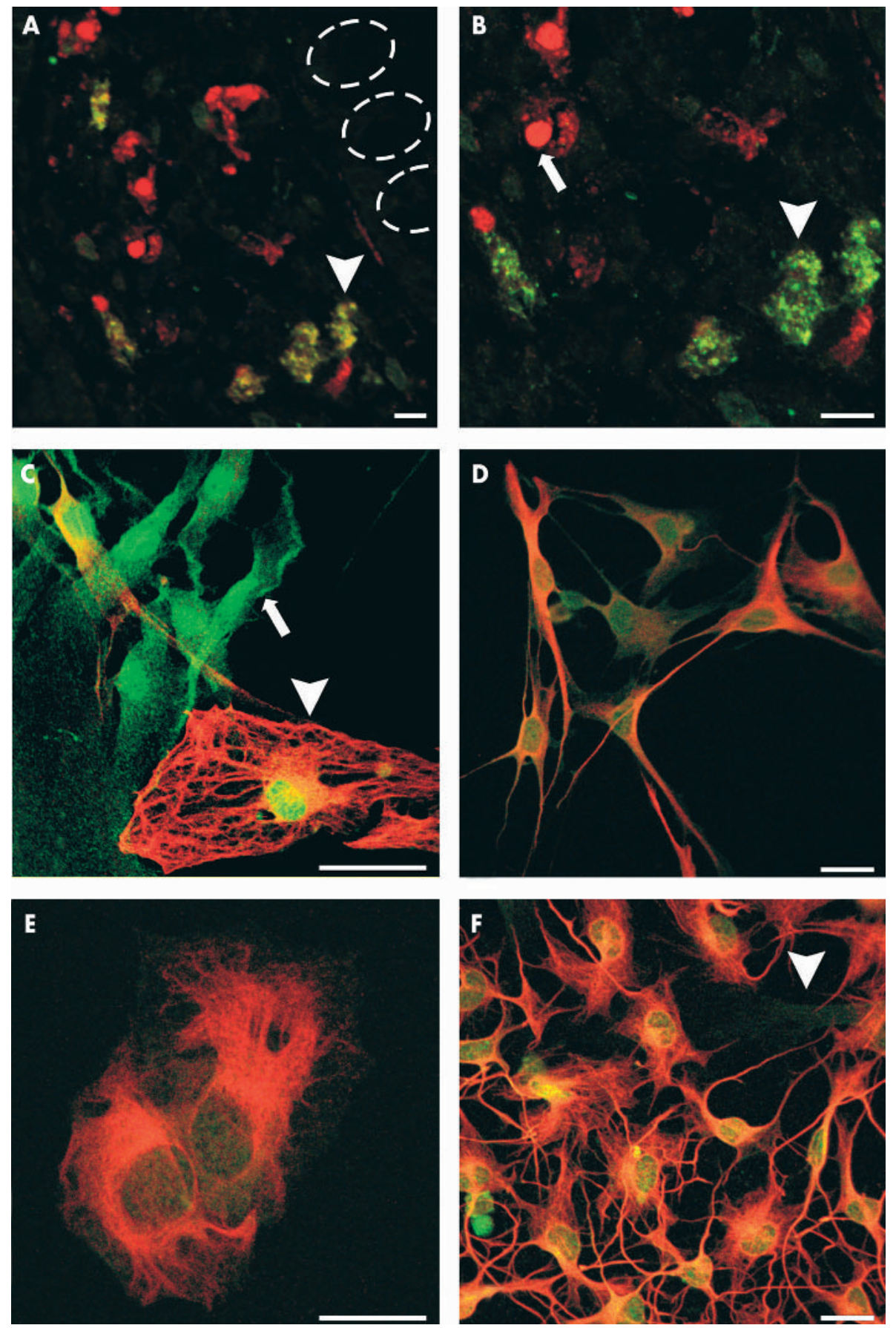

Figure 1 (A, B) Double immunofluorescence labelling with anti S-100 (red) and antiglial fibrillary acidic protein (GFAP, green) showing GFAP+ (green, yellow, arrowhead) and GFAP - (red, arrow) subpopulations of enteric glia in the plexus mucosus of the rat in vivo. The dotted ovals indicate the position of epithelial crypts. (B) At higher magnification the different morphologies of enteric glia and nuclear staining of S-100 are discernible. (C) Immunostaining of primary enteric glia cell cultures also revealed two types of enteric glia in vitro: GFAP+ (red, yellow, arrowhead) and GFAP(green, arrow). Both cell types have a similar morphology, characterised by bi- or multipolar forms, with long thin processes connecting each other (D), or by epithelial-like cell shapes with extended cytoplasm (E). (F) Multipolar shaped glia cells, but not flattened cells, could easily be distinguished from unlabelled fibroblasts (arrowhead). Scale bars $20 \mu \mathrm{m}$.

could speculate that the two enteric glia forms serve similar functions as those in the CNS. This notion is supported by our finding that the proinflammatory cytokines IL- $1 \beta$, TNF- $\alpha$, and LPS increased the ratio of GFAP+ enteric glia to a similar extent and that this process was reversible after removal of the respective cytokine. This upregulatory effect was specific as both a neutralising antibody to IL- $1 \beta$ and the IL- 1 receptor antagonist completely abolished the increase in GFAP+ enteric glia. Interestingly, the increase in GFAP+ enteric glia in the gut was also observed after obstruction of the gut accompanied by inflammation ${ }^{1}$ and in trinitrobenzene sulphonic acid induced colitis of the guinea pig. ${ }^{2}$ Moreover, GFAP+ enteric glia upregulation was evident in inflamed tissues of patients with ulcerative colitis and CD. ${ }^{3}$ However, this increase in GFAP+ enteric glia was much less pronounced in $\mathrm{CD}$, possibly indicating a poor response of the enteric glia to inflammatory signals. ${ }^{3}$ Thus it is possible that an increased number of GFAP+ enteric glia is not only 

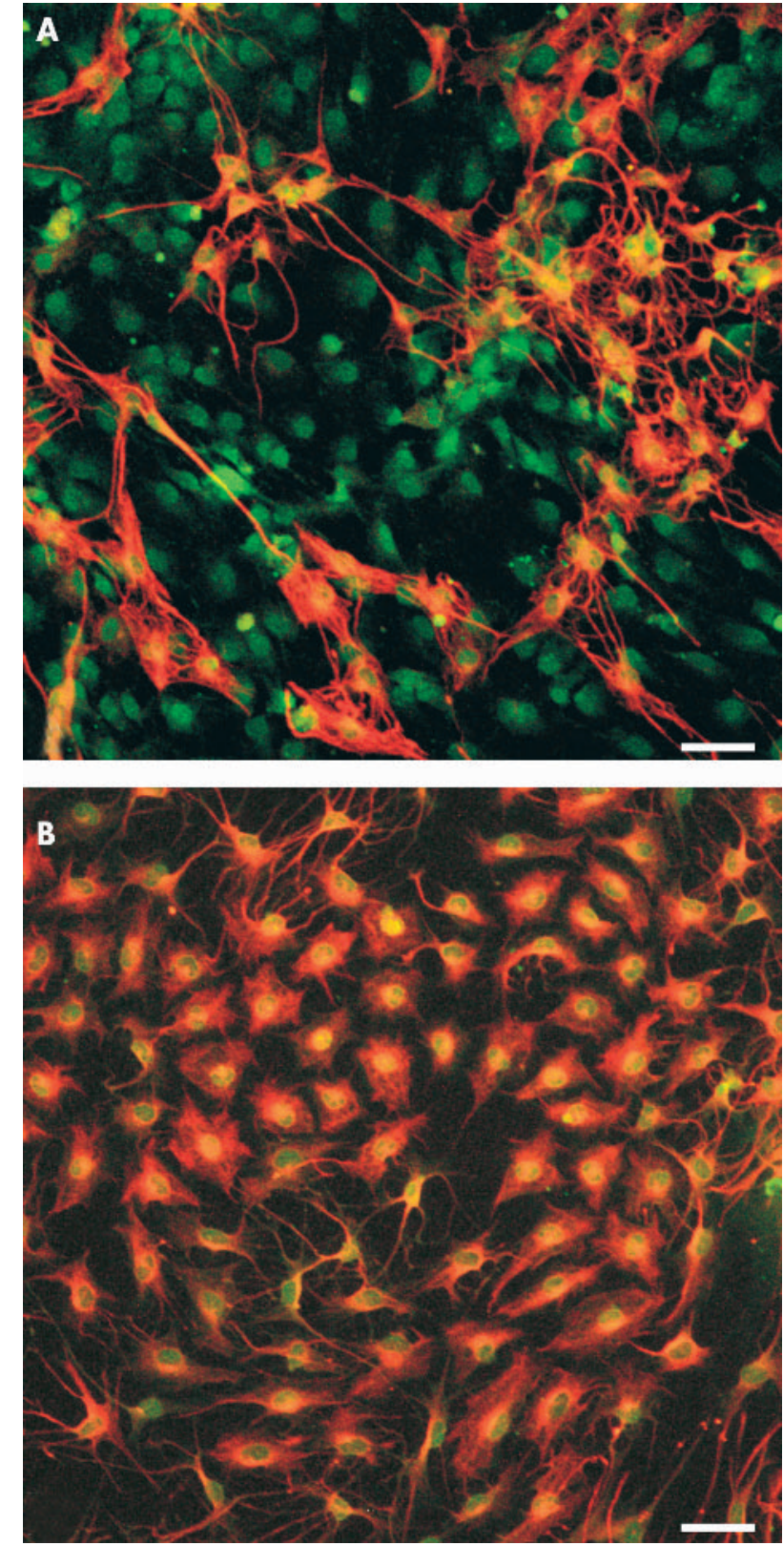

Figure 2 Immunofluorescence staining for glial fibrillary acidic protein (GFAP) and S-100 revealed that interleukin $1 \beta$ (IL-1 $\beta 80 \mathrm{ng} / \mathrm{ml}$ ) increased the number of GFAP+ enteric glia cells (B) in comparison with the untreated control (A). Scale bars $50 \mu \mathrm{m}$.

indicative of proinflammatory stimulation but may even be involved in maintaining the integrity of the bowel during stressful events (for example, inflammation). IL-1 $\beta$ and TNF- $\alpha$, which are strongly upregulated during inflammation and are released in the presence of LPS, ${ }^{25}{ }^{30}$ could be effector molecules for this mechanism. Furthermore, we showed that: (i) the extent of GFAP+ enteric glia upregulation was dependent on IL- $1 \beta$ concentration, which in turn was shown to correlate with the severity of inflammation; (ii) the upregulatory effect was nearly completely reversible after withdrawal of the cytokines; and (iii) the anti-inflammatory cytokine IL-4 had no upregulatory effect on enteric glia. Taken together, these data support the notion that the cytokine effect on enteric glia was specific and may either reflect or be involved in the pathomechanisms of inflammatory diseases of the gut.
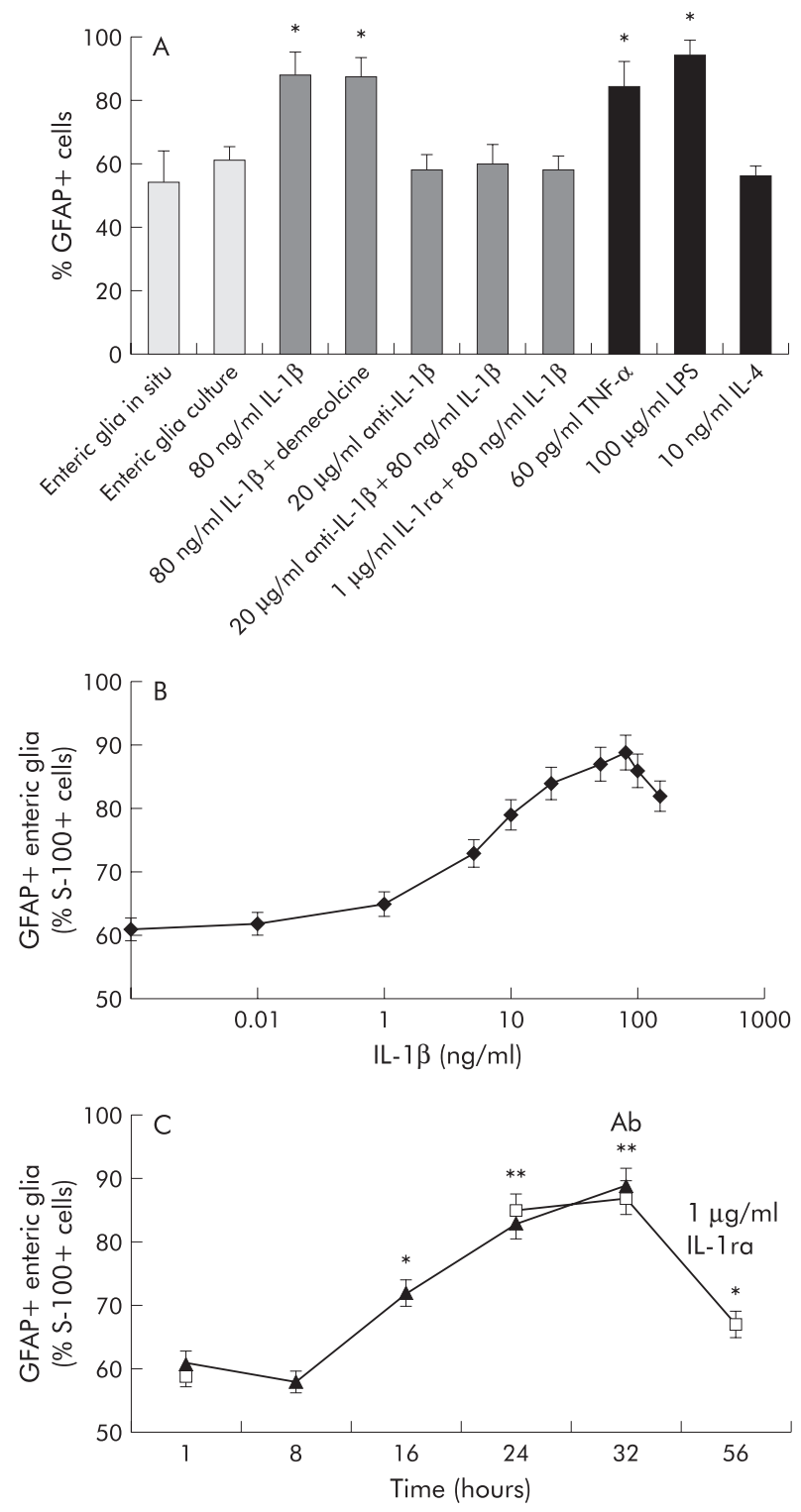

Figure 3 (A) Percentage of glial fibrillary acidic protein positive $(G F A P+)$ enteric glia in vivo and in vitro, after incubation with lipopolysaccharide, the cytokines tumour necrosis factor $\alpha$ (TNF- $\alpha$ ), interleukin (IL)- 4 , IL-1 $\beta$, and anti-IL-1 $\beta /$ IL-1 receptor antagonist (ra), and after treatment with demecolcine. Data are mean (SEM) number of GFAP+ cells/S-100+ cells. *Significantly different from control $(p<0.01)$. (B) Dose-response curve showing the effect of different concentrations of IL-1 $\beta$ on GFAP+ and GFAP- enteric glia cells (mean (SEM)). (C) Time dependent increase in GFAP+ enteric glia after incubation with IL-1 $\beta$ (filled triangles) and the decrease after withdraw of IL-1 $\beta$ (open squares). Ab, time point when medium was removed and replaced by medium containing $1 \mu \mathrm{g} / \mathrm{ml} \mathrm{IL-1}$ ra. Results are expressed as mean (SEM). Significantly different from control: * $p<0.05$, ${ }^{* *} \mathrm{p}<0.01$.

IL- $1 \beta$ affects not only the number of GFAP+ enteric glia cells but consequently also intracellular GFAP content. Western blot analysis showed an approximate sixfold increase in GFAP on addition of IL- $1 \beta$ whereas the number of GFAP+ cells increased by only 1.5 fold (61 (4)\% to 88 (7)\%). This suggests that the intracellular GFAP of every GFAP+ enteric glia cell is increased. The function of this "reactive gliosis in the gut" is not understood. In the CNS, similar changes ("astrogliosis") have been observed on inflammation. ${ }^{17} 1821-23$ 


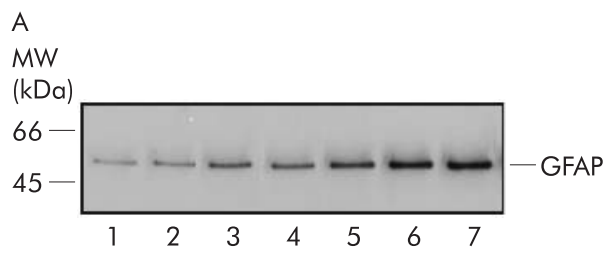

B

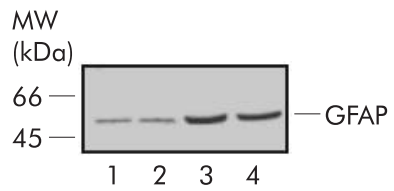

Figure 4 (A) Western blot analysis from cultured rat myenteric plexus cells (30 $\mu \mathrm{g}$ total protein loaded/lane). Lane 1: glial fibrillary acidic protein (GFAP) immunoreactivity of unstimulated cultures; lane 2: with $100 \mathrm{ng} / \mathrm{ml}$ interleukin (IL)- $1 \beta$ and $20 \mu \mathrm{g} / \mathrm{ml}$ anti-IL-1 $\beta$; lane 3: with $5 \mathrm{ng} / \mathrm{ml} \mathrm{IL-1} \beta$; lane 4 : with $10 \mathrm{ng} / \mathrm{ml}$ IL-1 $\beta$; lane 5 : with $20 \mathrm{ng} / \mathrm{ml}$ IL$1 \beta$; lane 6: with $80 \mathrm{ng} / \mathrm{ml} \mathrm{IL-1} \beta$; and lane 7: with $100 \mathrm{ng} / \mathrm{ml} \mathrm{IL-1 \beta}$. (B) Western blot analysis from cultured rat myenteric plexus cells with demecolcine (30 $\mu \mathrm{g}$ total protein loaded/lane). Lane 1: GFAP amount of unstimulated cultures; lane 2: GFAP amount with demecolcine; lane 3: cultures stimulated with IL-1 $\beta(80 \mathrm{ng} / \mathrm{ml})$; and lane 4 : cultures after stimulation with IL-1 $\beta(80 \mathrm{ng} / \mathrm{ml})$ and demecolcine.

However, the increase in GFAP+ CNS astrocytes by IL-1 $\beta$, released during inflammation, is caused by proliferation. ${ }^{21}$ Interestingly, this is not the case for enteric glia as BrdU incorporation revealed similar proliferation rates for GFAP+ enteric glia in the presence or absence of IL-1 $\beta$. Moreover, the increase in GFAP+ enteric glia on addition of IL-1 $\beta$ was also observed after blocking mitosis by the colchicin derivative demecolcine. These data suggest that the increase in GFAP+ enteric glia on IL-1 $\beta$ stimulation is caused by an increase in GFAP expression in GFAP - enteric glia and not by selective proliferation of GFAP+ enteric glia. This is consistent with experiments demonstrating that GFAP+ enteric glia do not proliferate on stimulation with IL- $1 \beta .^{31}$

The ratio between the two enteric glia pools could be considered as a dynamic equilibrium which can be regulated by IL- $1 \beta$, TNF- $\alpha$, and LPS. Thus it is possible that a single very plastic cell type contains a broad range of different GFAP concentrations. In response to the environment and proinflammatory cytokines, this cell population could upregulate, among others, its GFAP content. As our data suggest that this process is relatively slow, protein biosynthesis may be required. Thus two different enteric glia cell types may exist: one with a detectable level of GFAP, which can rapidly upregulate GFAP expression, and one type without detectable amounts of GFAP, responding slowly to environmental signals with GFAP synthesis. This observation could reflect the different origins of enteric glia. ${ }^{2}$

Although, the exact role of increased GFAP of glia cells is not well established, it was shown that GFAP is necessary for mature astrocytes to react in different CNS diseases. ${ }^{32}{ }^{33}$ Thus GFAP upregulation of astrocytes is thought to isolate inflammatory lesions from unaffected areas. ${ }^{31}$ This suggests that GFAP upregulation is a stereotyped yet adequate reaction to different pathological states in the nervous system. A similar mechanism may exist in the enteric glia during gut injury. As mice lacking GFAP develop and reproduce normally, ${ }^{34}$ the filament GFAP itself may be an indicator rather than an effector. GFAP+ enteric glia however are essential for homeostasis of the gut as loss of GFAP+ enteric glia leads to a haemorrhagic jejunoileitis. ${ }^{9}$ As GFAPenteric glia are capable of starting GFAP expression on IL-1 $\beta$ and TNF- $\alpha$ stimulation, it is possible that cytokines induce

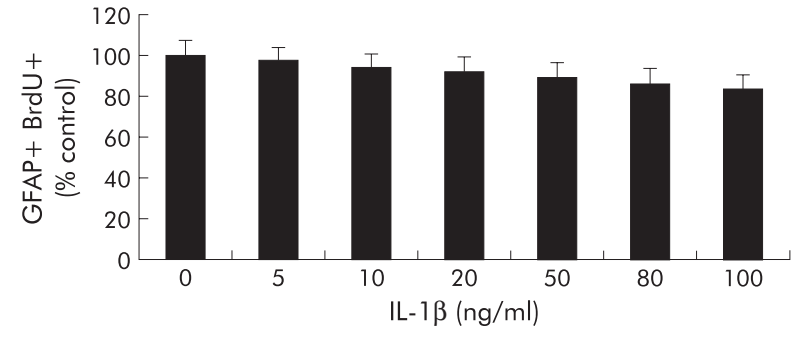

Figure 5 Effects of different concentrations of interleukin (IL)- $1 \beta$ on proliferation rates of primary glial fibrillary acidic protein positive $(G F A P+)$ enteric glia by using bromodeoxyuridine (BrdU). Each bar represents the mean (SEM) of four independent experiments. There was no significant difference with respect to the proliferation rate of controls after incubation with IL-1 $\beta$. Incorporation of BrdU was determined as $100 \%$ in controls.

these changes in the inflamed gut. This notion is supported by our findings. Additional GFAP+ enteric glia may support the integrity of the inflamed gut by producing protecting factors-for example, neurotrophic factors. In this scenario, GFAP - enteric glia can be considered as a reserve cell pool for inflammatory responses. Thus one might speculate whether a critical reduction in this cell pool or an inadequate reaction of enteric glia to proinflammatory cytokines may occur in CD or NEC as both diseases show a lack of GFAP+ enteric glia, despite high cytokine concentrations. ${ }^{369}$ This phenomenon could be considered as a primary event as it is known that the development of the ENS and enteric glia depends on different factors and lack of the respective factor leads to ENS malformations in different parts of the bowel. ${ }^{11}$ Nevertheless, enteric glia cells could also represent a target for viral assault. Thus an initial episode of virus induced lysis of enteric glia could lead to a secondary autoimmune targeting of enteric glia, as has been demonstrated for oligodendrocytes in an animal model for multiple sclerosis. ${ }^{35}$ Therefore, a secondary event could also be possible. ${ }^{36}$

In this study, we demonstrated the existence of a GFAPglia cell type in the ENS, both in situ and in vitro. In response to stimulation with proinflammatory cytokines, these glia increase GFAP. Therefore, upregulation of GFAP+ enteric glia might be a similar reaction to proinflammatory cytokines as astrogliosis in the CNS. This mechanism may contribute to maintaining the integrity of the bowel. Thus a similar form of gliosis may also exist in the ENS of the inflamed gut which may be regulated by IL- $1 \beta$, TNF- $\alpha$, and LPS.

\section{Authors' affiliations}

G B T von Boyen, M Steinkamp, M Reinshagen, G Adler, Department of Medicine I (Gastroenterology), University of Ulm, Ulm, Germany K-H Schäfer, Department of Pediatric Surgery, University of Mannheim, Mannheim, Germany

J Kirsch*, Department of Anatomy and Cellular Neurobiology, University of Ulm, Ulm, Germany

*Present address: Department of Medical Cell Biology, Institute for Anatomy and Cell Biology, University of Heidelberg, Heidelberg, Germany

\section{REFERENCES}

1 Gabella G. Size of neurons and glial cells in the intramural ganglia of the hypertrophic intestine of the guinea-pig. J Neurocytol 1984;13:73-84.

2 Bradley JS jr, Parr EJ, Sharkey KA. Effects of inflammation on cell proliferation in the myenteric plexus of the guinea-pig ileum. Cell Tissue Res 1997;289:455-61

3 Cornet A, Savidge TC, Cabarrocas J, et al. Enterocolitis induced by autoimmune targeting of enteric glial cells: a possible mechanism in Crohn's disease? Proc Natl Acad Sci U S A 2001;98:13306-11.

4 Podolsky DK. Inflammatory bowel disease. N Engl J Med 2002;347:417-29.

5 Oehmichen M, Reifferscheid P. Intramural ganglion cell degeneration in inflammatory bowel disease. Digestion 1977;15:482-96. 
6 Bush TG. Enteric glial cells. An upstream target for induction of necrotizing enterocolitis and Crohn's disease? Bioessays 2002;24:130-40.

7 Wedel T, Krammer HJ, Kuhnel W, et al. Alterations of the enteric nervous system in neonatal necrotizing enterocolitis revealed by whole-mount immunohistochemistry. Pediatr Pathol Lab Med 1998;18:57-70.

8 Hsueh W, Caplan MS, Tan X, et al. Necrotizing enterocolitis of the newborn: pathogenetic concepts in perspective. Pediatr Dev Pathol 1998;1:2-16.

9 Bush TG, Savidge TC, Freeman TC, et al. Fulminant jejuno-ileitis following ablation of enteric glia in adult transgenic mice. Cell 1998;93:189-201.

10 Von Boyen GB, Reinshagen M, Steinkamp M, et al. Gut inflammation modulated by the enteric nervous system and neurotrophic factors. Scand J Gastroenterol 2002;37:621-5.

11 Von Boyen GB, Reinshagen M, Steinkamp M, et al. Enteric nervous plasticity and development: dependence on neurotrophic factors. J Gastroenterol 2002;37:583-8.

12 Gershon MD, Rothman TP. Enteric glia. Glia 1991;4:195-204.

13 Ferri GL, Probert L, Cocchia D, et al. Evidence for the presence of S-100 protein in the glial component of the human enteric nervous system. Nature 1982;297:409-10.

14 Jessen KR, Mirsky R. Glial cells in the enteric nervous system contain glial fibrillary acidic protein. Nature 1980;286:736-7.

15 Walz W. Controversy surrounding the existence of discrete functional classes of astrocytes in adult gray matter. Glia 2000;31:95-103.

16 Walz W, Lang MK. Immunocytochemical evidence for a distinct GFAPnegative subpopulation of astrocytes in the adult rat hippocampus. Neurosci Lett 1998;257:127-30.

17 Hatten ME, Liem RK, Shelanski ML, et al. Astroglia in CNS injury. Glia 1991;4:233-43.

18 McGraw J, Hiebert GW, Steeves JD. Modulating astrogliosis after neurotrauma. J Neurosci Res $2001 ; 63: 109-15$.

19 Mucke L, Eddleston M. Astrocytes in infectious and immune-mediated diseases of the central nervous system. FASEB J 1993;7:1226-32.

20 Basu A, Krady JK, O'Malley M, et al. The type 1 interleukin-1 receptor is essential for the efficient activation of microglia and the induction of multiple proinflammatory mediators in response to brain injury. J Neurosci 2002;22:6071-82.

21 Giulian D, Lachman LB. Interleukin-1 stimulation of astroglial proliferation after brain injury. Science 1985;228:497-9.

22 Balasingam V, Tejada-Berges T, Wright $E$, et al. Reactive astrogliosis in the neonatal mouse brain and its modulation by cytokines. J Neurosci $1994 ; 14: 846-56$.
23 Yong VW, Moumdjian R, Yong FP, et al. Gamma-interferon promotes proliferation of adult human astrocytes in vitro and reactive gliosis in the adult mouse brain in vivo. Proc Nat Acad Sci U S A 1991;88:7016-20.

24 Khan I, Collins SM. Expression of cytokines in the longitudinal muscle myenteric plexus of the inflamed intestine of rat. Gastroenterology 1994; 107:691-700.

25 Schreiber S, Nikolaus S, Hampe J, et al. Tumour necrosis factor alpha and interleukin 1 beta in relapse of Crohn's disease. Lancet 1999:353:459-61.

26 West GA, Matsuura T, Levine AD, et al. Interleukin 4 in inflammatory bowel disease and mucosal immune reactivity. Gastroenterology 1996; 110:1683-95.

27 Schafer KH, Saffrey MJ, Burnstock G, et al. A new method for the isolation of myenteric plexus from the newborn rat gastrointestinal tract. Brain Res Brain Res Protoc 1997; 1:109-13

28 Yong VW, Kim SU. A new double labelling immunofluorescence technique for the determination of proliferation of human astrocytes in culture. J Neurosci Methods 1987;21:9-16

29 Reinshagen M, Geerling I, Eysselein VE, et al. Commercial recombinant human beta-nerve growth factor and adult rat dorsal root ganglia contain an identical molecular species of nerve growth factor prohormone. J Neurochem 2000;74:2127-33.

30 Ligumsky M, Simon PL, Karmeli F, et al. Role of interleukin 1 in inflammatory bowel disease-enhanced production during active disease. Gut 1990:3:686-9

31 Ruhl A, Franzke S, Stremmel W. IL-1 beta and IL-10 have dual effects on enteric glial cell proliferation. Neurogastroenterol Motil 2001;13:89-94.

32 Pekny M, Johansson CB, Eliasson C, et al. Abnormal reaction to central nervous system injury in mice lacking glial fibrillary acidic protein and vimentin. J Cell Biol 1999;145:503-14.

33 Anderova M, Kubinova S, Mazel T, et al. Effect of elevated $\mathrm{K}(+)$, hypotonic stress, and cortical spreading depression on astrocyte swelling in GFAPdeficient mice. Glia 2001;35:189-203.

34 Pekny M, Leveen P, Pekna M, et al. Mice lacking glial fibrillary acidic protein display astrocytes devoid of intermediate filaments but develop and reproduce normally. EMBO J 1995; 14:1590-8.

35 Miller SD, Eagar TN. Functional role of epitope spreading in the chronic pathogenesis of autoimmune and virus-induceddemyelinating diseases. Adv Exp Med Biol 2001;490:99-107.

36 Shanahan F, Sullivan GC. Glial cells, mucosal integrity, and inflammatory bowel disease. Gastroenterology 1999;116:493-4.

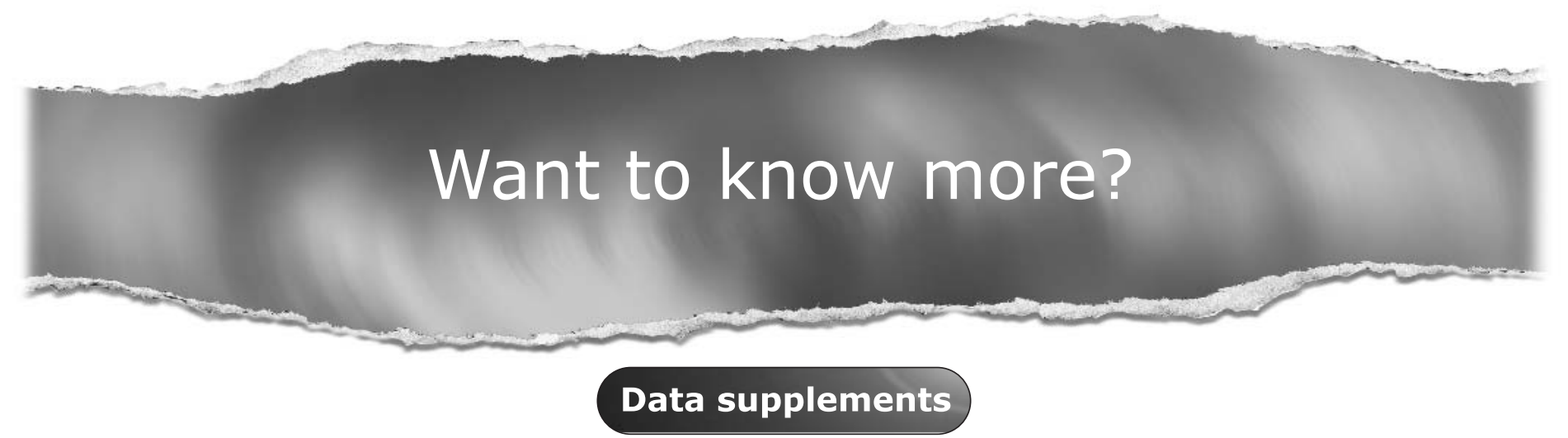

Limited space in printed journals means that interesting data and other material are often edited out of articles; however, limitless cyberspace means that we can include this information online.

Look out for additional tables, references, illustrations.

www.gutjnl.com 